\title{
María, mujer en la política. Nuevos desafíos para la teología latinoamericana*
}

\author{
Elina Vuola**
}

\section{Resumen}

La Virgen María ha sido un símbolo controvertido en América Latina desde la Conquista europea. Igualmente, para el feminismo latinoamericano la figura de María ha sido problemática. Sin embargo, en el nivel de la religiosidad popular, María es tanto una mezcla cultural de lo europeo, lo americano y lo africano, como también es de importancia especial para las mujeres. Por eso, para la creación de una teología mariana latinoamericana son importantes los estudios etnográficos sobre el significado de María en la religiosidad popular.

Palabras clave: Virgen María, teología feminista, marianismo, teología latinoamericana, la Negrita de Costa Rica.

* Vuola. e. (2012, 19 de sep.). Conferencia. en III Congreso Internacional de Teología Mariana. Chiquinquirá, BOy: Facultad de Teología de la Universidad Santo Tomás.

** Doctora en Teología por la Universidad de Helsinki, Finlandia; investigadora, Academia de Finlandia, Universidad de Helsinki - Instituto de estudios de Desarrollo. Correo eléctronico: elina.vuola@helsinki.fi 
Mi país de origen, Finlandia, es el más luterano del mundo, con ochenta por ciento de la población perteneciendo a la Iglesia luterana. ¿De dónde surge mi interés por la Virgen María, entonces? ¿Por la falta de ella? Una de mis informantes en Costa Rica, donde me entrevisté con mujeres católicas sobre su relación con la Virgen, me comentó al saber que en la iglesia luterana la Virgen María tiene un rol muy reducido: “iqué, qué no tienen María? Pobrecitos, son huérfanos".

Pues, que no la tenemos es verdad y no lo es. Los protestantes compartimos 1500 años de historia y teología en común con la Iglesia católica y la Iglesia ortodoxa, en los cuales la presencia de la Virgen María es tan rica y amplia. esta historia incluye la mariología temprana, los dos primeros dogmas ecuménicos sobre María. el mismo Martin Lutero tenía un cariño especial por María ${ }^{1}$.

Mi interés teológico por la figura de María surge de dos fuentes principales. Primero, de la teología latinoamericana de la liberación, principal pero no exclusivamente católica, y segundo, de la teología feminista ecumenical y global. La Virgen María es importante en ambas, aunque por razones diferentes: en la teología de la liberación, como la mujer del pueblo, la profeta del Magnificat y como el centro de la religiosidad popular latinoamericana. en la teología feminista, por ser la mujer más importante del cristianismo y como modelo para las mujeres cristianas, a veces contradictoria y negativa como resultado de conotaciones sexistas ligadas a su persona. Las teólogas feministas han tenido un interés ecuménico por la figura de María, tanto crítico como constructivo.

Y finalmente, aunque Finlandia es un país tan luterano, por su ubicación geográfica e historia en común con Rusia, hay una presencia de María en el país a través de la otra iglesia cristiana importante, la rusa-ortodoxa, en diferencia a los demás países nórdicos luteranos.

Los puntos centrales de mi ponencia son los siguientes:

1. La Virgen María es un símbolo controvertido en la cultura latinoamericana.

1 Véase especialmente su comentario sobre el Magníficat en Lutero (2006). en esta selección de obras de Lutero en español, el comentario del Magníficat se encuentra en el capítulo 7. el Magníficat traducido y comentado (pp. 1520-21). 
2. el símbolo de la Virgen María está ligado a la política latinoamericana desde la conquista y de la época colonial hasta la independencia y la época de las dictaduras. Por "política" entiendo algo más que partidos políticos y la política formal.

3. La relación entre el feminismo latinoamericano, las mujeres y la figura de María, que también es una cuestión "política".

4. María en la religiosidad popular latinoamericana y la importancia de su estudio. Voy a presentar un estudio de caso de la Virgen de los Ángeles alias la Negrita de Costa Rica.

Desde el inicio de la Conquista, la Virgen María ha sido una figura controvertida en las tierras latinoamericanas. María fue presentada por los misioneros europeos como la conquistadora, la protectora y agente de la evangelización, inseparable de la conquista militar, cultural y económica. en muchas partes de América, la Conquista se realizó en su nombre o como la madre universal quien quiere que todos sus hijos se unieran bajo su protección o como el método más efectivo de desarraigar los cultos locales de diosas precolombinas. La colonización hispánica fue colonización mariana (González Dorado, 1988, pp. 38-39). Todo esto, obviamente, resultó bastante contradictorio para los indígenas. esta doble cara de María - la madre universal protectora, por un lado, y el agente de la europeización y colonización, por otro- se ha mantenido en una forma u otra a través de los siglos en América Latina. Podemos tomar varios ejemplos de este doble rol de ella tanto de la época de la Conquista como la época colonial y de la Independencia, hasta el siglo XX.

La rápida y efectiva sustitución de las creencias precolombinas por la fe cristiana resultó en un alto nivel de sincretismo en el catolicismo popular latinoamericano. quiero enfatizar que uso el término sincretismo en un sentido neutral. Es un término que puede significar tanto una fuerte actitud peyorativa hacia la religiosidad popular como una amenaza para la pureza de la doctrina cristiana. En el sentido neutral, refiere más bien al hecho de la existencia simultánea de continuación y ruptura de una tradición religiosa dada al confrontarse con otra religión. También en este sentido, el culto de la Virgen María en América Latina tiene una "doble cara". Simboliza tanto el 
militarismo europeo como la maternidad universal, hasta cósmica, tanto una ruptura como continuación de dos culturas y sistemas religiosos diferentes.

en el proceso de sincretismo, dos religiones asumen características de una a otra. es siempre un proceso mutuo. Como la religión es parte de la cultura en cualquier parte del mundo, este proceso no es nada nuevo tampoco en la historia del cristianismo, nacido del judaísmo. También durante los primeros siglos del cristianismo, la mariología temprana no solamente fue una parte integral del desarrollo de la doctrina cristiana (como, por ejemplo, la declaración de María como Theotokos como parte de la doctrina cristológica), sino que también fue una forma de sustituir a los cultos de diosas precristianas. el proceso más de mil años más tarde fue parecido en América Latina. Resultó no solamente en el fuerte culto mariano que conocemos hasta nuestros días sino también en nuevas interpretaciones propiamente latinoamericanas. el desarrollo del culto mariano en las Américas no fue un proceso pasivo de recepción de creencias europeas. Desde los primeros días de su presencia en las tierras americanas, presentó rasgos y funciones que no había tenido en españa. No tenemos que desvalorizar este proceso, sino tomarlo como parte esencial e histórica de la devoción mariana latinoamericana.

La Virgen María latinoamericana es una mezcla de lo europeo, lo americano y lo africano: incorpora la historia latinoamericana que tiene sus raíces en tres continentes y no puede ser reducida solamente a lo europeo. esta historia, en una forma u otra, está viva en todas las devociones marianas de América Latina. Respetar esa mezcla es respetar la historia del continente. el símbolo de María, quizás más que ningún otro, mantiene viva esa historia. Aún más, sigue viva en la religiosidad popular latinoamericana, con una variación enorme en la región. Muchos de los cultos locales no son muy conocidos fuera del país o la region, como es el caso de la Virgen de los Ángeles de Costa Rica. La relación entre la religiosidad popular y la teología y doctrina marianas no tiene que ser conflictiva. Respetar la religiosidad popular es respetar la fe del pueblo, de los hombres y mujeres comunes y corrientes, quienes sostienen todas las instituciones religiosas.

en especial, una teología latinoamericana sensitiva hacia la religiosidad popular levanta una figura de María que no es solamente bíblica sino también relevante a mucha gente. es la María interpretada desde la perspectiva de los pobres y oprimidos, sea por raza, etnia o género. Las leyendas sobre 
las admoniciones de María en América Latina la cuentan como la Madre de Dios; casi sin excepción, aparece a gente humilde, marginalizada y sin poder - esclavos negros, niños y niñas, mujeres, indígenas - en tiempos de conflicto, caos y desintegración cultural. La teología de la liberación ha intentado desarrollar una mariología liberadora desde estas experiencias. Además, tiene una fuerte base bíblica, especialmente en el Magníficat.

Las "diferentes Marías" de América Latina han tenido y continúan teniendo funciones controvertidas y hasta conflictivas, en especial en relación con el nacionalismo y los estados-nación latinoamericanos, por un lado, y como centros emocionales y culturales de la religiosidad popular por el otro. en sus roles de patronas de los estados latinoamericanos, están ligadas a la historia del desarrollo del nacionalismo, pero también a los diferentes ejemplos de conflicto entre el Estado y la sociedad civil, más marcado durante la época de dictaduras del siglo pasado. Para el pueblo, a través de los siglos, la Virgen María siempre ha tenido importancia vivida como la "especialista" de lo cotidiano: las relaciones humanas, la familia, la salud, la maternidad. en otras palabras, la Virgen María morena, por ejemplo, es reconciliadora y madre de todos, como el espejo humano y divino de su pueblo. Desde su aparición y hasta el día de hoy, este rol también lo ha tenido la Virgen de Guadalupe de México, Nuestra Señora de Chiquinquirá de Colombia, La Aparecida de Brasil, Nuestra Señora de la Caridad del Cobre de Cuba y la Virgen de los Ángeles de Costa Rica.

Como símbolo político, la Virgen María ha tenido un rol importante durante la Independencia y las diferentes revoluciones latinoamericanas, entre ellas la mexicana. Como símbolo, ha servido objetivos diferentes, hasta opuestos, como durante la Conquista: ¿está ella al lado de los poderosos o de los humildes? Durante las dictaduras, llegó a ser un objeto de identificación y un símbolo de la lucha de los grupos de los derechos humanos, principalmente compuestos por mujeres en búsqueda de sus hijos e hijas desaparecidos.

el término marianismo, ampliamente utilizado en la investigación contemporánea (socio-científica) sobre mujeres latinoamericanas, tiene su origen en un artículo temprano de evelyn Stevens titulado "Machismo y 
marianismo" (1973a) $)^{2}$. en su texto, Stevens delinea dos moralidades y fuentes de identidad distintas para los hombres y mujeres latinoamericanos: machismo para los primeros, marianismo para las últimas. Según Stevens, el marianismo es "un culto secular de feminidad sacado de la adoración a la Virgen María". el marianismo

dibuja sus sujetos como semi-divinos, moralmente superiores y espiritualmente más fuertes que los hombres. esta constelación de atributos hace posible a las mujeres de aguantar las humillaciones infligidas sobre ellas por los hombres, y de perdonar a aquellos que les hacen daño [...]. Por eso, la maldad de los hombres es una precondición necesaria para la condición superior de las mujeres (1973b, p.63).

el machismo es "el otro rostro de marianismo", juntos crean dos moralidades contrarias para los hombres y las mujeres latinoamericanos, "una simbiosis estable en la cultura latinoamericana". Según Stevens, las mujeres intencionalmente modelan el mito de marianismo, caracterizado por los ideales femeninos de semidivinidad, superioridad moral, fuerza espiritual, abnegación, una capacidad infinita de humildad y sacrificio, negación de sí misma y paciencia. Tanto el machismo como el marianismo son síndromes, desarrollados por completo solo en América Latina.

Para analizar la descripción de Stevens del destino de las mujeres latinoamericanas y su relación con la figura de la Virgen María (incluso la patologización de una cultura entera, la imagen de los hombres en el mito del machismo, y la complacencia de las mujeres con todo esto) requeriría más espacio del que dispongo en este artículo. espero poder ofrecer ejemplos de una imagen diferente de la Virgen María, viva entre mujeres católicas comunes y corrientes.

en la teología feminista hay un interés renovado por la Virgen María, lo que puede implicar la relevancia del símbolo de María para mujeres más allá de los tradicionales límites confesionales de la piedad mariana. en mi investigación, pregunto cómo y por qué las mujeres en diferentes contextos

2 Otra versión del artículo se puede encontrar en Stevens (1973b). Lo que sigue está basado en los dos textos. esta parte del artículo está tomada de mi artículo Vuola (2006). 
culturales, y en diferentes tiempos, se acercan a María en sus experiencias cotidianas de ser mujeres en sociedades y religiones patriarcales, y le dan sus "propios" sentidos, en ocasiones independientemente de la enseñanza formal sobre ella. Argumento que hay una tradición viva de la devoción a María con un rostro muy humano (femenino), que se acerca a las mujeres en sus experiencias más íntimas y reales. Mi investigación está fundada en métodos teológico-textuales y etnográficos. Esto hace posible escuchar las voces de las mujeres reales, en contraste con la teoría abstracta de marianismo la cual interpreta las realidades y pensamientos de las mujeres latinoamericanas desde una muy estrecha - y abiertamente negativa - visión de la Virgen María y su importancia en la cultura latinoamericana ${ }^{3}$.

Una comprensión de María como alguien que afirma y comparte, y al mismo tiempo trasciende y está más allá del ser mujer humana, a veces está en contradicción con la María "oficial" de las iglesias y con los dogmas teológicos, especialmente en cuanto a su corporalidad, sexualidad y maternidad. Pero también es interesante que los mismos dogmas marianos han mantenido, quizás de la mejor forma, algo que se podría llamar el principio femenino en el cristianismo, desde sus inicios hasta hoy, aunque pueda parecer distorsionado desde la perspectiva de las mujeres contemporáneas.

Las creencias populares - en especial, las de mujeres - acerca de la Virgen María pueden estar, y de hecho muchas veces lo están, en tensión con el credo y el dogma de la iglesia oficial. Pero no necesariamente lo están, porque durante los siglos numerosas creencias que llamamos populares, de hecho, han sido integradas en el dogma. Se trata de una influencia recíproca.

Así que a mí me ha interesado el triángulo de diferentes visiones y tensiones: primero, la enseñanza formal y oficial de la(s) iglesia(s) sobre la Virgen, a menudo con connotaciones sexistas o alejadas de las realidades de las mujeres, segundo, la crítica feminista secular de esta y, tercero, la religiosidad vivida de las mujeres para quienes la figura de la Virgen muchas veces no es solamente importante, sino que además es indispensable; ellas la ven como fuente de empoderamiento, consolación y ayuda, no de alienación. Lo

3 Véase mi trabajo anterior Vuola (1993). Sobre las interpretaciones mariológicas de los teólogos de la liberación, véanse los capítulos III y IV de Vuola (2002). Para traducción al español ver Vuola (2001). 
que sigue está basado en mi investigación sobre el significado de la Virgen María para mujeres católicas costarricenses. en mi investigación, me concentro entonces en el tercer punto del triángulo, presentándolo como una crítica correctiva de algunos aspectos de la mariología oficial, en especial del tipo de teoría feminista que no toma en cuenta la religiosidad vivida y la identificación positiva de las mujeres con sus tradiciones religiosas.

quiero enfatizar que una responsabilidad importante por parte de las que somos teólogas feministas es hacer una deconstrucción y reconstrucción de la mariología tradicional desde el punto de vista de las mujeres y nuestra corporalidad, pero el presente espacio no me permite hacerlo más allá de un esbozo rápido.

La crítica feminista teológica - no secular como es el caso del marianismo - se concentra en general en algunos puntos centrales, igualmente importantes para católicas y protestantes. Primero, la Virgen María es un modelo imposible para las demás mujeres, aunque se la presenta como tal especialmente en la tradición católica. este punto está relacionado con el segundo, la exaltación de la virginidad y asexualidad a través de María. Hay que ver que esta crítica se refiere a la realidad concreta, hasta fisiológica, de la vida humana, y no necesariamente al nivel simbólico o espiritual. La crítica de la tradición cristiana desde la teología feminista intenta desmantelar el sexismo y misoginia, por un lado, y levantar las realidades concretas y la corporeidad de las mujeres como correctiva de ese sexismo, por otro.

Tercero, si la combinación de virginidad y maternidad está usada e interpretada en contra de todas las demás mujeres y su maternidad, María no puede servir como símbolo y modelo liberadores. La crítica feminista recuerda que la maternidad virginal puede fácilmente llegar a la negación de la maternidad ordinaria, el destino de todas las demás mujeres si son madres. Igualmente, puede llegar a ser una negación de la sexualidad humana, tanto para los hombres como las mujeres.

Cuarto, la oposición antigua de eva y María en la mariología es un punto clave en la crítica feminista. en esta tipología, eva aparece como la madre de la humanidad caída, por culpa de quien vino el pecado al mundo (eva como porta diaboli, según Tertuliano). María representa la nueva humanidad redimida y la puerta del cielo. Como el pecado es la parte inseparable de la persona de eva, son la gracia y la redención las características determinantes 
de María. en este sistema teológico se representa a eva y a María como dos tipos de mujeres contrapuestas. Se separa radicalmente lo malo y lo bueno y esta separación está personificada en dos mujeres. Por eso, según la crítica feminista teológica, el ideal femenino producido por una parte de la mariología ha mantenido la oposición entre la buena y la mala mujer. eva como la madre de la humanidad, respetada todavía en el judaísmo, ha llegado a ser una personificación del pecado, del peligro de la sexualidad y la maldad femenina.

quinto, las teólogas feministas preguntan si la exaltación de María a costa de las demás mujeres está relacionada con el estatus de la mujer. en otras palabras, por alguna razón, las iglesias cristianas donde el sacerdocio de las mujeres no es una posibilidad (ortodoxa y católica) son al mismo tiempo más marianas. en las iglesias protestantes, en su mayoría, la ordenación de la mujer es una realidad, pero la Virgen María no tiene un estatus elevado o central.

Aquí no voy a presentar las reinterpretaciones constructivas de estas cuestiones desde la teología feminista. ya que en la teología feminista no se usan muchos métodos etnográficos, sino que más bien el discurso se concentra casi exclusivamente en lo doctrinal, voy a tomar mis ejemplos de la realidad de la religiosidad vivida de las mujeres. en el mundo de la religiosidad popular o vivida están presentes varias interpretaciones mariológicas que no están basadas en las combinaciones imposibles de virginidad y materni- dad o en las oposiciones entre María y las otras mujeres.

La Virgen de los Ángeles es la patrona de Costa Rica desde 1824. en la jerga popular se conoce como la Negrita por el color de la estatua por la leyenda de su admonición, según la cual se le apareció a una mujer joven "parda" (mezcla de indígena y negra) en 1635. A través del tiempo, se ha convertido en parte del culto local y marginal de los afroamericanos de la costa atlántica del país al igual que es símbolo de la nación y nacionalismo costarricenses. En su figura y culto, están combinadas las cuestiones de raza, etnia, género y clase. Se conoce a la Negrita como muy poderosa y milagrosa. 
Los milagros de ella son numerosos, y esa es su función más importante aún hoy para el pueblo creyente de Costa Rica ${ }^{4}$.

Mi investigación se concentraba en hacer entrevistas con mujeres costarricenses de diferentes edades sobre su relación con la Virgen María ${ }^{5}$. Por haber realizado el estudio en Costa Rica, en la mayoría de las entrevistas, aunque no exclusivamente, las mujeres hablaban de la Negrita y no de la Virgen en general. Su capacidad de milagros se concretiza en los exvotos, en Costa Rica llamados milagros o promesas, que la gente lleva a su basílica al pedir un favor o al agradecerla por un favor concedido. La mayor parte de estos exvotos hechos de metal representan partes del cuerpo humano o un ser humano entero (hombre, mujer, niña, niño). este tipo de religiosidad material, me di cuenta durante mi estancia en Colombia, está presente también en la devoción de Nuestra Señora de Chiquinquirá.

Según las entrevistas, en la mayoría de los casos los pedidos tienen que ver con la corporalidad y cotidianidad de la vida humana concreta: salud, familia, relaciones humanas, fertilidad y maternidad, y dificultades económicas. Aquí no dispongo de la posibilidad de escribir más sobre esto. Mi interés aquí es más bien metodológico: solamente escuchando las voces de mujeres ordinarias podemos construir una teología (feminista) que respete las interpretaciones y realidades desde la religiosidad popular, en especial la de las mujeres, por ser excluidas de la representación más formal de su religión.

Mis conclusiones se pueden condensar en un entendimiento del doble carácter de la Madre de Dios en la vida de mis entrevistadas: por un lado, María "como yo" (identificación) y María "como algo más que yo" (trascendencia). en otras palabras, las mujeres entrevistadas tenían una relación de "tanto - como" y no "o - o" con ella. María es tanto una mujer ordinaria (ser humano, madre y hermana y una mujer campesina) como una mujer poderosa (la Reina del Cielo, mujer divina, madre universal y cósmica y la intercesora). A través de este doble rol de la Virgen, se experimenta en la vida cotidiana en términos de acompañamiento, entendimiento y apoderamiento.

4 La Virgen de los Ángeles de Costa Rica ha sido muy poco estudiada. Una excepción es el estudio del historiador costarricense José Gil zúñiga (1985).

5 Un análisis más detallado sobre las entrevistas se encuentra en Vuola (2009). Véase también Vuola (2012). 
Su ser de mujer no es sin importancia, pero mis entrevistadas no la vieron solamente como madre, sino como una mujer como ellas, con el mismo cuerpo y con las mismas experiencias - positivas o traumáticas - de ellas.

Presento entonces mis resultados como una crítica correctiva tanto de una teología tradicional alienada de las condiciones de vida reales de muchas mujeres, como de una crítica feminista que tiende a interpretar a la Virgen María solamente o principalmente en términos de alienación y sumisión. Al fin, es también un aporte para la teología feminista que muy pocas veces está basada en las interpretaciones de mujeres comunes y corrientes. En términos más teóricos, esto significa que la teología podría abrirse a las disciplinas antropológicas y sus métodos etnográficos.

en la devoción de la Negrita de Costa Rica hay varias tensiones que como investigadora interpreto más como una riqueza que como un problema. Todas estas tensiones también surgieron de una u otra forma en las entrevistas.

Termino mi artículo con una breve presentación de estas tensiones para futura investigación: primero, la tensión entre la enseñanza formal de la Iglesia y las creencias, interpretaciones y prácticas religiosas de la gente (lo oficial contra lo popular); segundo, la relación entre la religión y la cultura (difícil si no imposible de separar); tercero, la tensión o relación entre lo secular y lo religioso, lo temporal y lo sagrado (igualmente difícil de hacer una separación clara entre ellos); cuarto, la tensión entre las élites políticas, económicas, religiosas y el pueblo (cuestión de clase), y relacionada con esto, la tensión entre el estado (la Negrita como su símbolo principal) y la sociedad civil (la Negrita como fuente de ayuda para los más vulnerables y marginalizados); quinto, la tensión entre lo blanco, lo europeo, y lo negro e indígena (cuestión de raza y etnicidad y del racismo), tan presentes en su figura y su leyenda; sexto, la tensión entre el patriarcalismo y el sexismo de una buena parte de la tradición cristiana sobre María y las experiencias vividas de apoderamiento e identificación de las mujeres (cuestión de género y sexismo); y por último la tensión entre una crítica feminista secular (marianismo) y la religiosidad vivida de las mujeres.

entonces, en América Latina la Virgen María sigue siendo un símbolo controvertido y político en el sentido amplio de los términos. Los desafíos que se le presentan a la teología latinoamericana tienen que ver con la importancia de la religiosidad popular para la teología, íntimamente ligada a 
cuestiones de género, clase, raza y etnia. La religión o la religiosidad vivida es quizás un mejor término que la religiosidad popular, porque cubre todo lo relacionado con la vida cotidiana y las múltiples formas como la religión cruza la totalidad de la vida humana. Para que la teología pueda "beber de su propio vaso", en las palabras de Gustavo Gutiérrez, se necesita un conocimiento adquirido por métodos etnográficos, que por su propia naturaleza dirigen la atención hacia la religiosidad vivida e interpretada por la gente, y no solamente hacia cuestiones doctrinales. en una región como América Latina, que incluye el desafío de las culturas indígenas y afroamericanas y las cuestiones de género también dentro de ellas, el campo de la religiosidad popular ha sido ignorado tanto por la teología formal como por la teología de la liberación y la teología feminista, y fuera del estudio teológico, por los estudios de género seculares. Por otro lado, la antropología y las ciencias de la religión prestan atención hacia la religiosidad vivida, pero fácilmente ignoran la importancia de la teología y cuestiones propiamente teológicas.

Las mujeres cristianas se identifican con María y su destino con intensidad, y vuelven borrosa la frontera o el límite entre ambas, entre "lo religioso" y "lo ordinario", entre lo inmanente y lo trascendental. María es un canal y un objeto perfecto para este tipo de experiencias (femeninas). esta imitatio Mariae, imitación de María, quizás puede ofrecer más a las mujeres que el tipo clásico de imitatio Christi de la vida cristiana, y a la inversa, las mujeres tienen mucho que ofrecer a la esfera religiosa en el contexto de una mariología que representa a María como una fuerza maternal toda abarcadora y como una personificación del carácter liminal de la vida humana. Esta perspectiva es ecuménica, reflejada en el interés y el amor por María de las mujeres de diferentes iglesias cristianas, inclusive las protestantes.

\section{Referencias}

Gil zúñiga, J. (1985). Un mito de la sociedad costarricense: el culto a la Virgen de los Ángeles (1924-1935). Revista de Historia. (11), 47-129.

González Dorado, A. (1988). De María conquistadora a María liberadora. Mariología popular latinoamericana, Santander: Sal Terrae,

Lutero, M. (2006). Obras. egido, T. (ed.). Sígueme: Salamanca. 
Stevens, e. (1973a). Machismo and marianismo. Society 10, 6, 57-63.

Stevens, e. (1973b). Marianismo: the other face of machismo in Latin America. en Pescatello, A. (ed.). Female and male in Latin America. Essays (pp. 89-101). Pittsburgh, PA: University of Pittsburgh Press.

Vuola, e., (1993). La Virgen María como ideal femenino, su crítica feminista y nuevas interpretaciones. Pasos 45, 11-20.

Vuola, e. (2001). La ética sexual y los límites de la praxis. Conversaciones críticas entre la teología feminista y la teología de la liberación. quito: Abya-yala.

Vuola, e. (2002). Limits of liberation. Feminist theology and the ethics of poverty and reproduction. New York, NY \& Sheffield: Sheffield Academic Press and Continuum.

Vuola, e. (2006). ¿Gravemente perjudicial para su salud? Religión, feminismo y sexualidad en América Latina y el Caribe. Pasos 127, 14-25.

Vuola, e. (2009). Patriarchal eecumenism, feminism, and women's religious experiences in Costa Rica. en Braude, A. \& Herzog, H. (eds.). Gendering religion and politics: untangling modernities (pp. 217-238). New york, Ny: Palgrave.

Vuola, e. (2012). La Morenita on skis: women's popular Marian piety and feminist research on religion. en Briggs, S. \& McClintock, M. (eds.). The Oxford Handbook of Feminist Theology (pp. 495-524). Oxford: Oxford University Press. 
